\title{
MARGINAL ACCURACY AND FRACTURE RESISTANCE OF POSTERIOR CROWNS FABRICATED FROM CAD/CAM PEEK CORES VENEERED WITH HIPC OR NANOHYBRID CONVENTIONAL COMPOSITE
}

\author{
Marwa Beleidy * and Ahmed Ziada **
}

\begin{abstract}
Statement of problem: Veneered polyether ether ketone (PEEK) is a recent alternative choice for fixed dental prostheses. There is a lack of data about the effect of composite veneering techniques of CAD/CAM PEEK cores on the marginal accuracy and fracture resistance of such restorations.

Purpose: To investigate the different composite veneering techniques of CAD/CAM PEEK cores influence on the marginal accuracy and fracture resistance of posterior crowns.

Methods: Twenty duplicated epoxy resin dies of a prepared mandibular first molar to receive a ceramic crown were fabricated. $20 \mathrm{CAD} / \mathrm{CAM}$ PEEK cores were fabricated and divided into two groups $(n=10)$ based on the veneering technique; group (A): HIPC veneered PEEK cores and group (B): nanohybrid crea.lign composite veneered PEEK cores (control group). Marginal gap was evaluated at 4 equidistant points on each crown by a digital microscope before and after ageing equivalent to clinical 6 months service. The fracture load was assessed after ageing. The data were statistically analyzed using one-way ANOVA, pair-wise Tukey's post-hoc and Student's t-tests to reveal the significance between groups $(\mathrm{P} \leq 0.05)$.

Results: The marginal gap was significant between before $(59.638 \pm 5.91 \mu \mathrm{m}$ and $58.587 \pm 7.74$ $\mu \mathrm{m})$ and after ageing $(79.167 \pm 11.62 \mu \mathrm{m}$ and $72.222 \pm 6.53 \mu \mathrm{m})$ for A and B groups respectively $(\mathrm{p}=0.0019 / 0.0039<0.05)$. ANOVA test showed a significant difference between groups before and after ageing $(\mathrm{p}=0.0002<0.05)$ which was not detected by Tukey's test $(\mathrm{p}>0.05)$. B group showed a significant higher fracture resistance mean value $(1674 \pm 224.8 \mathrm{~N})$ than A group $(1294 \pm 282 \mathrm{~N})$ $(\mathrm{p}=0.0164<0.05)$.
\end{abstract}

Conclusions: The marginal gap and fracture load values recorded by posterior crowns fabricated from CAD/CAM PEEK cores veneered with HIPC or nanohybrid composite were all within the clinically acceptable range.

KEYWORDS: HIPC, nanohybrid composite, PEEK, CAD/CAM, marginal gap and fracture resistance.

* Lecturer, Department of Fixed Prosthodontics, Faculty of Dentistry, October 6th University, Giza, Egypt.

** Lecturer, Department of Fixed Prosthodontics, Faculty of Dentistry, Benisuef University, Benisuef, Egypt. 


\section{INTRODUCTION}

Polyether ether ketone (PEEK) has introduced into the medical field due to its high biocompatibility and superior thermal, chemical and radiological stability. ${ }^{1}$ Those properties made PEEK used as an abutment or a framework for removable partial denture and fixed dental prosthesis (FDP). ${ }^{2}$ Two manufacturing ways for PEEK-FDPs are known; pressing using the vacuum-pressing device and milling utilizing computer-aided design/ computer-aided manufacturing (CAD/CAM) where PEEK blank is prepressed industrially following standardized parameters. The CAD/CAM technologies give lesser deformation and better fracture resistance performance..$^{3,4}$

PEEK is characterized by its opacity and grey to white color. Due to this low esthetic property, the material cannot be used as a monolithic prosthesis, making an additional veneering using composite resins is mandatory. Hence esthetic demands remain an important clinical reality, assessment of veneered PEEK FDPs is important.

Dhakal et al declared the possible enhancement of the composite's mechanical properties by adding fillers to the polymer material. ${ }^{5}$ However, it has also been mentioned that if the percentage of filler added was increased, the composites strength could be affected negatively.

For the last few years, the in vitro experiments have declared that artificial ageing process had a dramatic effect on both mechanical and physical properties of composites. ${ }^{6,7}$ This made the composite developers take more attention to the oral environment effect on the durability of composite materials.

Literatures about the marginal fit of veneered PEEK restorations are limited. It needs more investigations as the proper marginal fit is crucial to ensure a minimal cement film thickness as the poor adaptation is closely associated with gum inflammation, secondary caries, and prostheses failure. ${ }^{8}$

The current study aimed to investigate the vertical marginal gap and fracture resistance of posterior veneered crowns; PEEK (BioHPP) as a core material to be veneered with $\mathrm{CAD} / \mathrm{CAM}$ composite veneer (HIPC) or nanohybrid conventional composite veneer (crea.lign). The first null hypothesis of the present study assumed that ageing process would be ineffective impact on the vertical marginal gap between groups. Second null hypothesis was that the fracture resistance of PEEK core with conventional nanohybrid composite veneer would be higher than milled HIPC veneer.

\section{MATERIALS AND METHODS}

\section{Sample size calculation}

The power analysis used fracture resistance as the primary outcome. Based upon the results of Shakal MA, ${ }^{9}$ the effect size for the difference between two groups was $(d=2.7)$. Using alpha $(\alpha)$ level of $(5 \%)$ and power of $80 \%$, the minimum estimated sample size was 4 specimens which was increased to 10 specimens in each group. Sample size calculation was accomplished using a statistical power analysis software (G*Power; Version 3.1 .9.2, HHUD, Germany).

\section{Preparation of specimens}

A preparation for an all ceramic crown was performed to a typodont mandibular first molar tooth. The preparation guidance included $12^{\circ}$ total convergence angle, $1.0 \mathrm{~mm}$ deep chamfer margin circumferentially, $1.5 \mathrm{~mm}$ anatomical occlusal preparation, $1.5 \mathrm{~mm}$ axial preparation and $3.0 \mathrm{~mm}$ preparation height. All sharp points and line angles were rounded off. ${ }^{10}$ It was then replicated to have 20 dental epoxy resin dies. ${ }^{11}$ Each prepared die was scanned using 3D dental scanner (Identica hybrid; MEDIT corp., Seoul, Korea). Twenty cores were designed (exocad Dental CAD; exocad GmbH, 
Germany) and milled (K5; vhf camfacture AG, Germany) from PEEK blanks (breCAM.BioHPP Discs; Bredent, Senden, Germany, LOT: 400177), a thermoplastic resin which is partially crystalline and reinforced with ceramic particles. The core thickness was set at $0.5 \mathrm{~mm}$, while the cement space was set at $50 \mu \mathrm{m}$. The cores were then sandblasted (basic Quattro IS; Renfert, Hilzingen, Germany) using 110 $\mu \mathrm{m} \mathrm{Al}_{2} \mathrm{O}_{3}$ particles at $0.25 \mathrm{Mpa}$ and $45^{\circ}$ direction angle and $10 \mathrm{~mm}$ distance. After the air abrasion process, the cores were drowned for 5 minutes into ultrasonic bath (L\&R Transistor Ultrasonic T14, L\&R, Kearny, NY, USA). Afterwards, the PEEK cores were treated by visio.link (Bredent, Senden, Germany; LOT: 141432) where a thin coat was applied and 90 seconds polymerization was done (intensity: $220 \mathrm{~mW} / \mathrm{cm}^{2}$, Brelux Power Unit; bredent Senden, Germany). Then, a thin film application of the opaquer composite (Opaker combo.lign; bredent, Senden, Germany) was done, followed by 360 seconds polymerization.

The specimens then were divided into two groups ( $n=10$ /group) in accordance with the veneering technique: (Group A) veneering with digital CAD/ CAM breCAM, HIPC (shade A3, bredent, Senden, Germany; Lot No. 406700) and (Group B) veneering with conventional nanohybrid composite resin, crea.lign (shade A3, bredent Senden, Germany; Lot No. 130513).

For the digital veneering group, a waxed up master crown was manufactured. Two scans (Identica hybrid; MEDIT corp., Seoul, Korea) were carried out; one for the PEEK core on the epoxy resin die and one more for the master crown on the same die. The two scans were then subtracted from each other to have the digital veneer design with $1.0 \mathrm{~mm}$ thickness followed by milling (K5; vhf camfacture AG, Germany) from breCAM.HIPC blanks. The obtained veneers were dissembled and the mill connectors were removed. The inner surface of veneers was sandblasted (basic Quattro
IS; Renfert, Hilzingen, Germany) using $\mathrm{Al}_{2} \mathrm{O}_{3}$ powder of $110 \mu \mathrm{m}$ particles size at $0.25 \mathrm{MPa}$, a $45^{\circ}$ angle and $10 \mathrm{~mm}$ distance, and later immersed for 5 minutes in an ultrasonic bath (L\&R Transistor Ultrasonic T14, L\&R, Kearny, NY, USA). After the inner surface was dried, visio.link (bredent, Senden, Germany; LOT: 141432) was applied and polymerized for 90 seconds. The cores were placed on the epoxy resin dies, while the veneers were filled with combo.lign (bredent Senden, Germany; Lot No. 132420) before pressing them on the cores utilizing a device delivering a uniform load of 5 $\mathrm{kg}(49 \mathrm{~N})$ for 10 minutes. ${ }^{12}$ Then, 180 seconds polymerization was performed at $220 \mathrm{~mW} / \mathrm{cm}^{2}$ (brelux Power Unit; bredent Senden, Germany). Each crown was then polished (Opal L, Renfert GmbH, Hilzingen, Germany; Lot No. 520-0001; Abraso Starglanz; bredent, Senden, Germany) after removing the excess.

For conventional nanohybrid composite resin veneering group, a mold of transparent silicone (visio.sil; bredent Senden, Germany) for the master crown was made and filled with crea.lign composite resin. Then, the epoxy resin die with the attached PEEK core was pressed into the silicone mold and the polymerization was carried out for 360 seconds. The obtained crown was polished as same as described previously.

For cementation of crowns, the dies were abraded (basic Quattro IS; Renfert, Hilzingen, Germany) using $50 \mu \mathrm{m} \mathrm{Al}_{2} \mathrm{O}_{3}$ particles at 2.8 bars for 13 seconds and at a distance of $10 \mathrm{~mm}$, cleaned with water and air dried. ${ }^{13}$ A self-adhesive resin cement (RelyX Unicem; 3M, ESPE, St. Paul MN, USA) was used for the crown cementation using a special loading device delivering $10 \mathrm{~kg}$ for 10 minutes. ${ }^{11}$

\section{Vertical marginal gap assessment before ageing}

A digital image analysis system (Image $1.43 \mathrm{u}$; National Institutes of Health, MD, USA) was used to record the vertical marginal gap of each crown 
(Fig. 1A, 2A). It was combined with a USB digital microscope of $\times 45$ magnification power (Scope Capture Digital Microscope, Guangdong, China) that was connected to a camera and all were plugged to a computer. Marginal accuracy was measured in pixels; therefore, calibration of the system was carried out to get absolute units from pixels using tools generated by the ImageJ software to compare the ruler with the software scale.

For each specimen, images for the margins were captured. Then, morphometric measurements were performed for each image and 4 equidistant landmarks at the midpoint along the cervical circumference for each surface of the specimen (Buccal, Lingual, Mesial, Distal). Each point would be recorded five times. ${ }^{14}$

\section{Artificial ageing program of the cemented crowns}

All specimens were subjected to a mechanical stressing using a chewing simulator (ROBOTA chewing simulator; ROBOTA Model ACH09075DC-T, LTD., Germany) applying $49 \mathrm{~N}$ maximum vertical load and $1.6 \mathrm{~Hz}$ cyclic frequency for 120,000 cycles which corresponds to 6 months of clinical service. ${ }^{15} \mathrm{~A}$ load was applied occlusally with a steel ball of $5.6 \mathrm{~mm}$ diameter assembled to the upper movable compartment of the machine..$^{15}$ During mechanical loading, the specimens were subjected to 5,000 thermocycles $\left(5-55^{\circ} \mathrm{C}\right)$ with 30 seconds dwell time and 20 seconds transfer time to simulate 6 months of clinical service. ${ }^{9}$

After ageing procedure, the specimens were checked for a possible failure or crack using a stereoscope $\times 20$ (Leica MZ 6 stereomicroscope; Leica Microsystems, Germany) with direct examination and transillumination. ${ }^{16}$ Failed specimens were rejected.

\section{Vertical marginal gap assessment after ageing}

The same measurements for vertical marginal gap assessment were taken after ageing process (Fig. 1B, 2B).

\section{Fracture resistance evaluation}

All specimens were independently mounted in the universal testing machine (Model 3340; Instron Instruments Ltd., MA, USA) with $5 \mathrm{kN}$ load cell. The data were documented using a computer software (Nexygen-MT; AMETEK M\&CT Division, FL, USA). The specimens were fixed to the lower nonmovable compartment of testing machine using screws. A tin foil of $0.5 \mathrm{~mm}$ thickness was applied between the crown and the stress stamp avoiding force peaks. Subsequently, the load through a steel ball of $5 \mathrm{~mm}$ diameter was applied vertically with $1 \mathrm{~mm} / \mathrm{min}$ speed at the central fossa area of the crown with upper movable compartment of testing machine. The required load to fracture was recorded

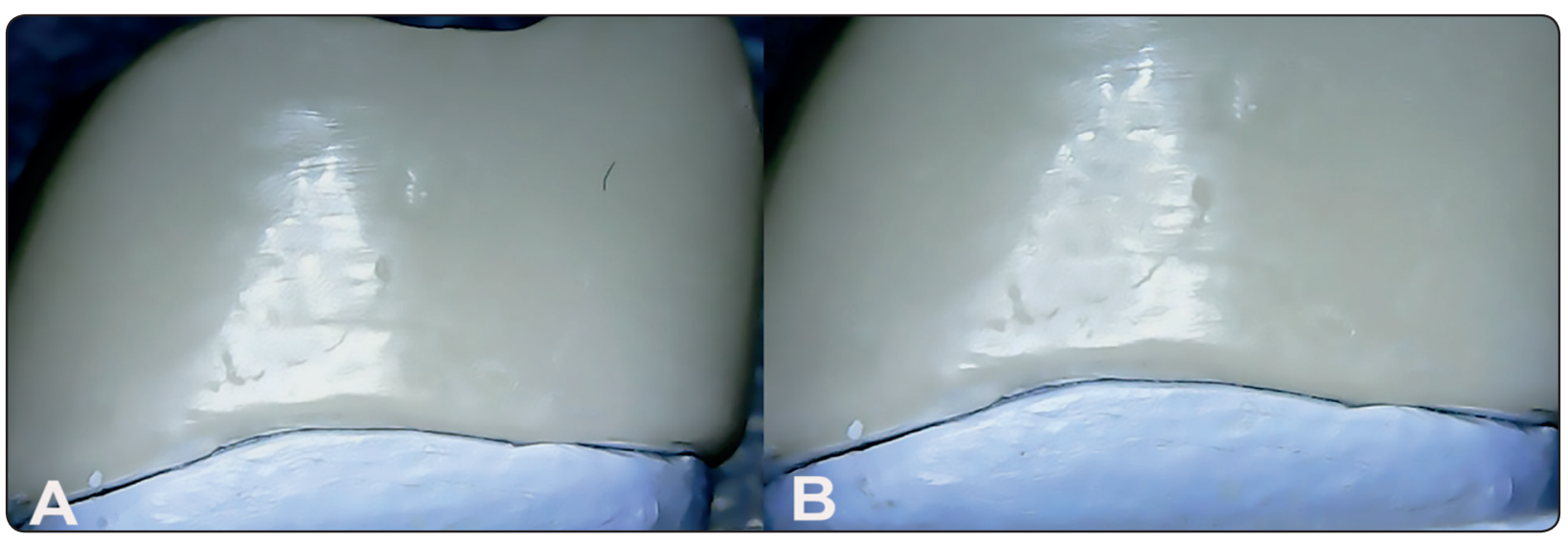

Fig. (1) Digital microscopic assessment $(\times 45)$ of vertical marginal gap distance of HIPC veneered CAD/CAM PEEK core before (A) and after ageing (B) at the mesial surface. 


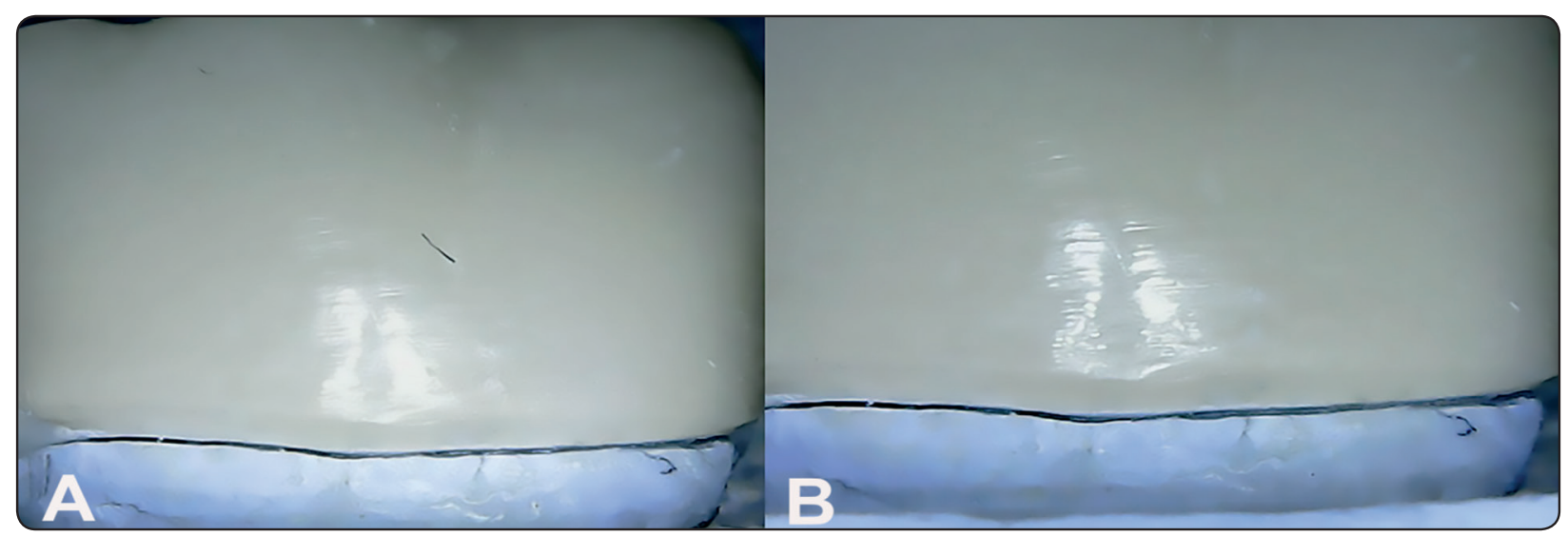

Fig. (2) Digital microscopic assessment $(\times 45)$ of vertical marginal gap distance of crea.lign composite veneered CAD/CAM PEEK core before (A) and after ageing (B) at the buccal surface.

in Newton. ${ }^{17,18} 10 \%$ load dropping below the maximum point of measured force was considered as a failure.

\section{Statistical analysis}

Data were represented as mean and standard deviation (SD) values. Normality of data was checked using Kolmogorov-Smirnov and ShapiroWilk tests. Two-way ANOVA test was performed to detect the significance between variables affecting the mean values (veneering technique and ageing). Significance detection between subgroups was performed using one-way ANOVA followed by pairwise Tukey's post-hoc tests. The significance level was set at $\mathrm{P} \leq 0.05$ and $95 \%$ confidence interval. For statistical analysis, a windows software (GraphPad Instat 3.1; GraphPad Software, CA, USA) was used.

\section{RESULTS}

\section{Marginal gap}

Regarding HIPC veneered PEEK cores (Agroup), the difference in vertical marginal gap distance between before $(59.638 \pm 5.91 \mu \mathrm{m})$ and after ageing $(79.167 \pm 11.62 \mu \mathrm{m})$ was statistically significant as recorded by paired t-test $(\mathrm{p}=0.0019<0.05)$ and shown in table (1) and figure (3).

Regarding nanohybrid crea.lign veneered PEEK cores (B group), the difference in vertical marginal gap distance between before $(58.587 \pm 7.74 \mu \mathrm{m})$ and after ageing $(72.222 \pm 6.53 \mu \mathrm{m})$ was statistically significant as marked by paired t-test $(\mathrm{p}=0.0039<0.05)$ and shown in table (1) and figure (3).

By ANOVA test $(\mathrm{p}=0.0002<0.05)$, a significant difference between groups was shown. While pair-wise Tukey's post-hoc tests revealed a nonsignificant difference between groups either before or after ageing $(p>0.05)$

\section{Effect of material type on marginal gap}

Regardless of ageing, A group showed statistically a non-significant higher marginal gap mean value than $B$ group as determined by two-way ANOVA test $(\mathrm{P}=0.4043>0.05)$.

\section{Effect of ageing on marginal gap}

Regardless of veneer material, the marginal gap mean value after thermomechanical ageing was significantly higher than before thermomechanical mean value as revealed by two-way ANOVA test $(\mathrm{P}=<0.0001<0.05)$.

\section{Fracture resistance}

It was found that B group $(1674 \pm 224.8 \mathrm{~N})$ recorded statistically a significant higher mean value than A group $(1294 \pm 282 \mathrm{~N})$ as indicated by student $\mathrm{t}$-test $(\mathrm{p}=0.0164<0.05)$ and shown in table (2) and figure (4) 
TABLE (1): Descriptive statistics of marginal gap results (Mean values \pm SDs) as a function of veneer material group and ageing.

\begin{tabular}{|c|c|c|c|c|c|c|}
\hline \multirow{2}{*}{\multicolumn{2}{|c|}{ Variables }} & \multirow{3}{*}{$\begin{array}{c}\text { Mean } \pm \text { SD }(\boldsymbol{\mu m}) \\
59.638^{\mathrm{B}} \pm 5.91\end{array}$} & \multicolumn{2}{|c|}{$95 \% \mathrm{CI}$} & \multicolumn{2}{|c|}{ Statistics } \\
\hline & & & Low & High & t-test & ANOVA \\
\hline \multirow{2}{*}{ A group } & Before & & 54.17 & 65.11 & \multirow{2}{*}{$0.0019 *$} & \\
\hline & After & $79.167^{\mathrm{A}} \pm 11.62$ & 68.42 & 89.91 & & \multirow{3}{*}{$0.0002 *$} \\
\hline \multirow{2}{*}{ B group } & Before & $58.587^{\mathrm{B}} \pm 7.74$ & 51.43 & 65.74 & \multirow{2}{*}{$0.0039 *$} & \\
\hline & After & $72.222^{\mathrm{A}} \pm 6.53$ & 66.19 & 78.26 & & \\
\hline
\end{tabular}

Different letters in the same column indicating statistically significant difference $(p<0.05) . \quad *$ significant $(p<0.05)$.

TABLE (2): Descriptive statistics of fracture resistance results (Mean \pm SD) between both groups after ageing.

\begin{tabular}{|c|c|c|c|c|c|c|}
\hline \multirow{2}{*}{\multicolumn{2}{|c|}{ Variable }} & \multirow{2}{*}{ Mean (N) } & \multirow{2}{*}{$\pm \mathrm{SD}$} & \multicolumn{2}{|c|}{$95 \% \mathrm{CI}$} & \multirow{2}{*}{$\begin{array}{c}\text { t-test } \\
\text { P value }\end{array}$} \\
\hline & & & & Low & High & \\
\hline \multirow{2}{*}{ Group } & A group & 1294 & 282 & 1033.2 & 1554.8 & \multirow{2}{*}{$0.0164 *$} \\
\hline & B group & 1674 & 224.8 & 1466.1 & 1881.9 & \\
\hline
\end{tabular}

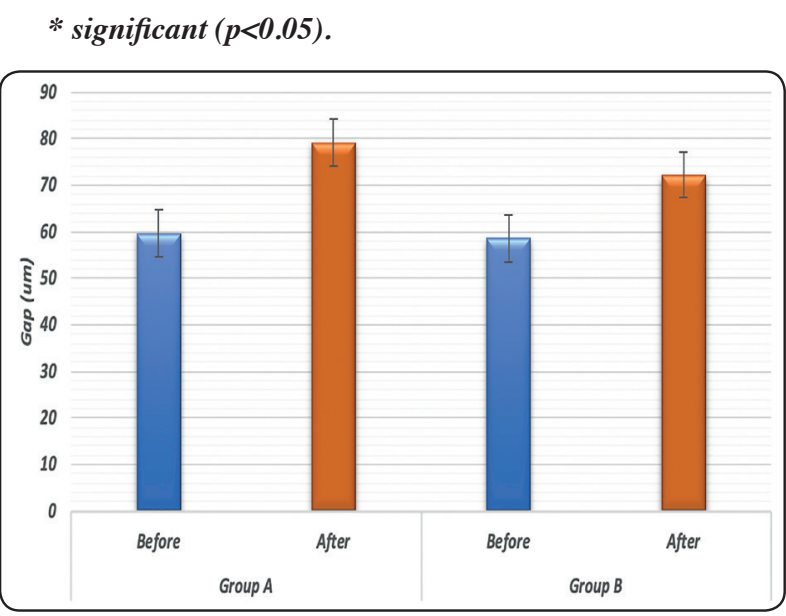

Fig. (3) Column chart of vertical marginal gap mean values for HIPC (A) and crea.lign (B) groups before and after ageing.

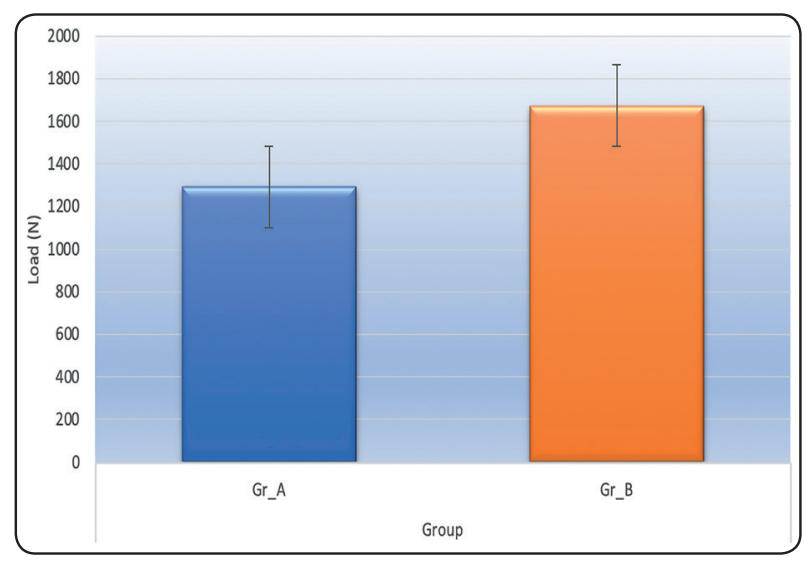

Fig. (4) Column chart showing fracture resistance mean values for HIPC (A) and crea.lign (B) groups after ageing,

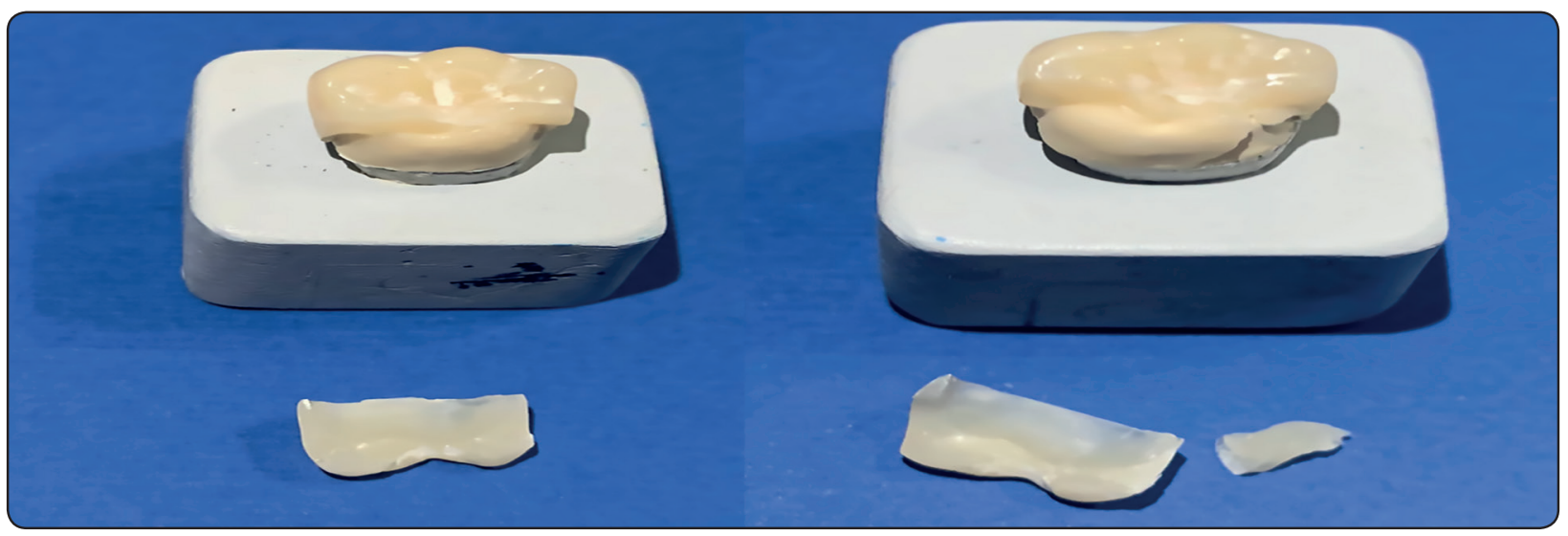

Fig. (5) Chipping between veneering HIPC and PEEK cores representing an adhesive failure. 


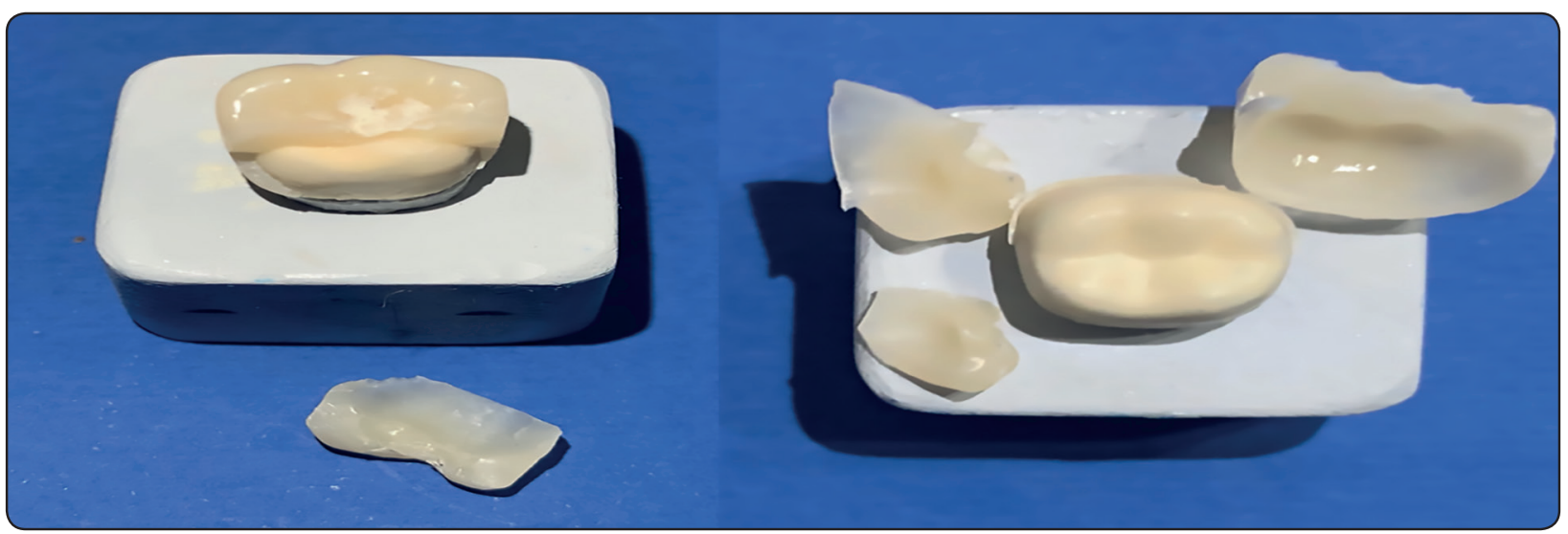

Fig. (6) Chipping between veneering crea.lign nanohybrid composite and PEEK cores representing an adhesive failure.

\section{DISCUSSION}

In the present study, a standardized epoxy resin master die with a heavy chamfer finish line was chosen following the guidance of all ceramic crown preparation. ${ }^{19-21}$ Many authors have used acrylic resin or metal dies to evaluate marginal precision and facture resistance. ${ }^{22,23}$ An epoxy resin die was used in this study for its near modulus of elasticity to the dentine and its clarity providing a good visibility in marginal gap measurements using digital microscopes..$^{24,25}$

In this study, PEEK (BioHPP) was used for the acceptable mechanical properties as it contains $20 \%$ ceramic fillers in its composition, low young modulus, and superior biocompatibility. ${ }^{26,27}$ PEEK fabrication techniques can be either by CAD/CAM or injection molding (pressing). ${ }^{3,28,29} \mathrm{CAD} / \mathrm{CAM}$ PEEK substructures showed excellent precise margins as the sintering shrinkage effect that was found in the pressing technique was avoided. Furthermore, the superior performance of the recent scanning technologies, the recent introduction of design software versions enhancing the prepared margin reading, and the advanced milling technology could promote the margin precision. ${ }^{3,30}$ In addition, higher fracture resistance and lower deformation patterns of these restorations have been reported. ${ }^{3}$ The thickness of the material was standardized according to the recommended values which are $0.5 \mathrm{~mm}$ for PEEK cores ${ }^{9}$ and $1.0 \mathrm{~mm}$ for HIPC or nanohybrid veneering composite resins restoring the prepared abutment to receive an all ceramic crown.

In the current study, the cementation procedure was standardized for all specimens. The same cement space $(50 \mu \mathrm{m})$ was set to avoid inconsistent results and emulate the clinical situations as investigation without cement does not match the real clinical condition. ${ }^{31,32}$ However, studies analyzing marginal gap before and after cementation had determined that the cement had a negative consequence on the marginal gap that was exaggerated after cementation. ${ }^{32-34}$

A special loading device was used in this study during cementation of the specimens as recommended by Gorten and Probster ${ }^{35}$ to ensure seating over the prepared abutment dies. A constant load was used in a parallel direction to the longitudinal axis of the abutment to ensure even flow of cement.

External marginal gap measurements were viewed directly using a digital microscope by the same operator for standardization. The digital microscopic viewing used in this study has the advantage of being noninvasive method. No sectioning was needed before measuring the 
gap, this made it time and cost saving than other techniques and decreasing the error chance. ${ }^{36}$

Different studies have mentioned the number of measurements required from four to eight, twelve, fifty-four, or more than 100 locations per crown. ${ }^{19,22,23,37,38}$ According to Groten et al, no less than 20 to 25 for the sum of all specimens were acceptable to achieve clinically reliable data. ${ }^{39} \mathrm{In}$ addition, 5 to 10 specimens for each tested group were considered as a sample size. ${ }^{23,38-40}$ In this study, 4 equidistant points along the cervical circumference in each crown were used to measure the marginal gap to have a total of 40 points for each group that were repeated 5 times. $^{14}$

Investigation of the specimen behavior under clinical like conditions is essential. All specimens were exposed to thermocycling and mechanical loading as materials would undergo subcritical cracks during mastication. ${ }^{41}$

As this study evaluated the marginal accuracy of PEEK cores veneered by different veneering composites, the null hypothesis that no influence of composite veneering of milled PEEK cores on the marginal accuracy was rejected. In this study, there was a significant increasing in the marginal gap after ageing in both groups. A group recorded $59.638 \pm 5.91 \mu \mathrm{m}$ and $79.167 \pm 11.62 \mu \mathrm{m}$ marginal gap distance before and after ageing respectively. B group showed 58.587 $\pm 7.74 \mu \mathrm{m} 72.222 \pm 6.53$ $\mu \mathrm{m}$ marginal gap distance before and after ageing respectively.

Ageing had effects on the composite veneering materials in two different ways. First, molecular interactions carried out between the water and the epoxy network where a macromolecular network plasticization was occured during water diffusion. These interactions lead to reduce the thermomechanical properties of the composites which reduce their use in high thermal changed and humid environment. ${ }^{42-45}$ In addition, hydrolysis of the epoxy network can promote an irreversible loss of composite properties. ${ }^{46,47}$ It was also stated that the used silane coupling agents in the glass sizing were affected by hydrolysis in a hot/wet environment that proved the sensitivity of the fibre/matrix interface to ageing process ${ }^{48,49}$

The second effect of ageing process was detected in the macroscopic scale in a form of fibre/ matrix debonding and material cracking that can be considered as a consequence of water sorption into the epoxy network. This is combined with hydrolysis and/or swelling stresses ${ }^{48,50}$ Debonding and cracks can affect the water penetration mechanisms in composites by creating new channels for the moisture access resulting in more rapid material weakening than resulting only by molecular diffusion in the matrix. Regarding the fibre/matrix debonding, fibers become directly and environmentally attacked inducing dramatic loss of static properties due to stress corrosion. ${ }^{48,51} \mathrm{~A}$ study has also showed the strong effect of water exposure on the interfacial shear strength reducing load transferring during mechanical loading. ${ }^{52}$

The results of present study were agreed by ElDessouky et al who showed that thermo-mechanical loading has significantly increased the marginal gap measurements when carried out in temperatures between $5^{\circ} \mathrm{C}$ and $55^{\circ} \mathrm{C} .{ }^{53}$ However, Wael et al assumed that the marginal discrepancies had no significant changes after artificial ageing. ${ }^{54}$

However, all results of vertical marginal gap in this study were within the acceptable range. Authors stated that vertical marginal gaps under $120 \mu \mathrm{m}$ were accepted clinically for FDPs. ${ }^{55,56}$ Others have reported that 160-172 $\mu \mathrm{m}$ were accepted clinically for conventional crowns. ${ }^{57}$

The fracture load of B group was reported to be $1674 \mathrm{~N}$ and significantly higher than A group which was $1294 \mathrm{~N}$ after ageing. Accordingly, the second null hypothesis of this study had to be accepted. Hence, both values were about 2.5 times the posterior area average bite force. ${ }^{17,58}$ As all tested crowns showed adequate fracture resistance compared with the expected biting force, ${ }^{59}$ the selected thickness 
of the core and veneering can be recommended. These results agreed with reported excellent in vitro performance of three-unit FDPs fabricated from veneered PEEK where they greatly exceeded the fracture resistance required to withstand the normal masticatory forces $(500-600 \mathrm{~N}){ }^{60-62}$ This could be explained by the mechanical behavior of BioHPP/ PEEK material. Its ideal modulus of elasticity that is closer to composite material and dentin might reduce stress induction at the different layers interface of the crowns. ${ }^{9,63,64}$ However, this study's results were against other study showing that the composite veneered FDPs resulted in lower fracture loads than those PEEK FDPs without veneering. ${ }^{60}$ This could be explained due to a different restoration type.

Crea.lign (B) group showed higher fracture load values than HIPC (A) group. That might be due to inclusion of $50 \%$ nanoceramic fillers. Adding nano filler particles to the resin matrix of dental composites improves the mechanical properties such as fracture resistance. ${ }^{65}$

On the other hand, Taufall et al reported that crea.lign veneered PEEK FDPs showed lower load bearing values in comparison to the HIPC veneering. ${ }^{62}$ This could be due to a higher modulus of elasticity of the die material (CoCrMo) compared to the hard tooth tissue, ageing process and restoration design. In addition, a peer-viewed study found that PEEK surface pre-treatment and veneering material had no effect of on the facture load of veneered PEEK FDPs. ${ }^{66}$

Although A group showed lower fracture load values in comparison to B group, but still higher than the average physiologic biting forces, due to better industrially fabrication processes which encompass high temperatures and pressures resulting in more consistant restoration qualities. ${ }^{67-70}$ Accordingly, such recently introduced CAD/CAM HIPC has the potential to be a substitute veneering material.

After fracture testing, the PEEK cores showed no noticeable fractures in all crowns, but chipping between veneering composite and PEEK cores has been detected (Fig. 5,6). The failure type was an adhesive failure in both tested groups. For HIPC group, this could be explained as that veneer has a higher strength, leading to the adhesive failure before the break of veneer. The pre-treatment seems to cause the pure adhesive breakdown. On the other hand, the adhesive failure for crea.lign group could be explained as a decreased bond strength of the nanohybrid composite which is significantly affected by the pretreatment, the used adhesive and the kind composite to bond with where no treatment or adhesive application were performed according to the manufacturer instructions.

One of the limitations of our study was that the abutment teeth's physiological movement was not modelling in the study. Therefore, fracture load test has limited clinical relevance. Furthermore, the effect of different milling machine axes on marginal accuracy should be evaluated and further analysis with larger specimens and clinical trials are recommended to reinforce the result.

\section{CONCLUSIONS}

Based on the present study's findings, all marginal gap and fracture load values were within the acceptable clinical range. PEEK substructures veneered with HIPC or conventional nanohybrid crea.lign composite can be alternative choices for single crown restorations.

\section{REFERENCES}

1. Modjarrad K, Ebnesajjad S, editors. Handbook of polymer applications in medicine and medical devices. Elsevier; 2013 Dec 5.

2. Schwitalla A, Müller WD. PEEK dental implants: a review of the literature. Journal of Oral Implantology. 2013 Dec; 39(6):743-9.

3. Stawarczyk B, Eichberger M, Uhrenbacher J, Wimmer T, Edelhoff D, Schmidlin PR. Three-unit reinforced polyetheretherketone composite FDPs: influence of fabrication method on load-bearing capacity and failure types. Dental materials journal. 2015 Jan 30;34(1):7-12. 
4. Helkimo E, Carlsson GE, Helkimo M. Bite force and state of dentition. Acta odontologica scandinavica. 1977 Jan 1;35(6):297-303.

5. Dhakal HN, Zhang ZY, Richardson MO. Effect of water absorption on the mechanical properties of hemp fibre reinforced unsaturated polyester composites. Composites science and technology. 2007 Jun 1;67(7-8):1674-83.

6. Hahnel S, Henrich A, Bürgers R, Handel G, Rosentritt M. Investigation of mechanical properties of modern dental composites after artificial aging for one year. Operative Dentistry. 2010 Jul;35(4):412-9.

7. Krüger J, Maletz R, Ottl P, Warkentin M. In vitro aging behavior of dental composites considering the influence of filler content, storage media and incubation time. PloS one. 2018 Apr 9;13(4):e0195160.

8. Zarauz C, Valverde A, Ferreiroa A, Martínez-Rus F. Clinical evaluation comparing the fit of all-ceramic crowns obtained from silicone and digital intraoral impressions based on wavefront sampling technology. Journal of dentistry. 2014;43(2):201-8.

9. Shakal MA. Comparative Fracture Resistance of Composite Veneered Polyether Ether Ketone Crowns with Ceramic and Composite Veneered Zirconia Crowns. Egyptian Dental Journal. 2018 Jan 1;64(1-January (Fixed Prosthodontics, Dental Materials, Conservative Dentistry \& Endodontics)):711-9.

10. Goodacre CJ, Campagni WV, Aquilino SA. Tooth preparations for complete crowns: an art form based on scientific principles. The Journal of prosthetic dentistry. 2001 Apr 1;85(4):363-76.

11. Beleidy M, Ziada A. Scanning electron microscope evaluation of the marginal gap and internal fit of additive versus subtractive fabrication techniques for posterior lithium disilicate crowns. Egyptian Dental Journal. 2019 Jul 1;65(3-July (Fixed Prosthodontics, Dental Materials, Conservative Dentistry \& Endodontics)):2779-93.

12. Meshreky M, Halim C, Katamish H. Vertical Marginal Gap Distance of CAD/CAM Milled BioHPP PEEK Coping Veneered by HIPC Compared to Zirconia Coping Veneered by CAD-On lithium disilicate "In-Vitro Study". Advanced Dental Journal. 2020 Mar 1;2(2):43-50.

13. Yucel MT, Yondem I, Aykent F, Eraslan O. Influence of the supporting die structures on the fracture strength of allceramic materials. Clinical oral investigations. 2012 Aug 1;16(4):1105-10.
14. Zaghloul HH, Younis JF. Marginal fit of implant-supported all-ceramic zirconia frameworks. Journal of Oral Implantology. 2013 Aug;39(4):417-24.

15. Beleidy M, Ziada A. The Influence of Split Pontic Designs on The Fracture Resistance Of CAD/CAM Fabricated Monolithic Zirconia FDPs Under Simulating Aging Conditions. Egyptian Dental Journal. 2020 Apr 1; 66(2-April (Fixed Prosthodontics, Dental Materials, Conservative Dentistry \& Endodontics)):1351-61.

16. Belli R, Geinzer E, Muschweck A, Petschelt A, Lohbauer U. Mechanical fatigue degradation of ceramics versus resin composites for dental restorations. Dental Materials. 2014 Apr 1;30(4):424-32.

17. Stawarczyk B, Beuer F, Wimmer T, Jahn D, Sener B, Roos M, Schmidlin PR. Polyetheretherketone-a suitable material for fixed dental prostheses?. Journal of Biomedical Materials Research Part B: Applied Biomaterials. 2013 Oct; 101(7):1209-16.

18. El-Naga AA, El-fallal AA, Ibraheim SA, Alaraby HA. Fracture Strength of Two Zirconia All-ceramic Crown Systems: Influence of Intaglio Surface Conditioning. Mansoura Journal of Dentistry. 2014;1(3):67-71.

19. Øilo M, Kvam K, Gjerdet NR. Simulation of clinical fractures for three different all-ceramic crowns. European journal of oral sciences. 2014 Jun; 122(3):245-50.

20. Quintas AF, Oliveira F, Bottino MA. Vertical marginal discrepancy of ceramic copings with different ceramic materials, finish lines, and luting agents: an in vitro evaluation. The Journal of Prosthetic Dentistry. 2004 Sep 1;92(3):2507.

21. Baig MR, Tan KB, Nicholls JI. Evaluation of the marginal fit of a zirconia ceramic computer-aided machined (CAM) crown system. The Journal of prosthetic dentistry. 2010 Oct 1;104(4):216-27.

22. Pera P, Gilodi S, Bassi F, Carossa S. In vitro marginal adaptation of alumina porcelain ceramic crowns. The Journal of prosthetic dentistry. 1994 Dec 1;72(6):585-90.

23. Rinke S, Huls A. Marginal accuracy and fracture strength of conventional and copy-milled all-ceramic crowns. International Journal of Prosthodontics. 1995 Jul 1;8(4).

24. Comlekoglu M, Dundar M, Özcan M, Gungor M, Gokce $\mathrm{B}$, Artunc $\mathrm{C}$. Influence of cervical finish line type on the marginal adaptation of zirconia ceramic crowns. Operative dentistry. 2009 Sep;34(5):586-92.

25. Alghazzawi TF, Liu PR, Essig ME. The effect of different fabrication steps on the marginal adaptation of two 
types of glass-infiltrated ceramic crown copings fabricated by CAD/CAM technology. Journal of Prosthodontics: Implant, Esthetic and Reconstructive Dentistry. 2012 Apr;21(3):167-72.

26. Georgiev J, Vlahova A, Kissov H, Aleksandrov S, Kazakova R. Possible application of BioHPP in prosthetic dentistry: A literature review. Journal of IMAB-Annual Proceeding Scientific Papers. 2018 Feb 7;24(1):1896-8.

27. Najeeb S, Zafar MS, Khurshid Z, Siddiqui F. Applications of polyetheretherketone (PEEK) in oral implantology and prosthodontics. Journal of prosthodontic research. 2016 Jan 1;60(1):12-9.

28. Zoidis P, Bakiri E, Polyzois G. Using modified polyetheretherketone (PEEK) as an alternative material for endocrown restorations: A short-term clinical report. The Journal of prosthetic dentistry. 2017 Mar 1;117(3):335-9.

29. Zoidis P, Papathanasiou I, Polyzois G. The use of a modified poly-ether-ether-ketone (PEEK) as an alternative framework material for removable dental prostheses. A clinical report. Journal of Prosthodontics. 2016 Oct; 25(7):580-4.

30. Beuer F, Naumann M, Gernet W, Sorensen JA. Precision of fit: zirconia three-unit fixed dental prostheses. Clinical oral investigations. 2009 Sep 1;13(3):343.

31. McLean JW. The estimation of cement film thickness by an in vivo technique. Br dent j. 1971;131:107-11.

32. Demir N, Ozturk AN, Malkoc MA. Evaluation of the marginal fit of full ceramic crowns by the microcomputed tomography (micro-CT) technique. European journal of dentistry. 2014 Oct;8(4):437.

33. Ural Ç, Burgaz Y, Saraç D. In vitro evaluation of marginal adaptation in five ceramic restoration fabricating techniques. Quintessence International. $2010 \mathrm{Jul}$ 1;41(7).

34. Borges GA, Faria JS, Agarwal P, Spohr AM, Correr-Sobrinho L, Miranzi BA. In vitro marginal fit of three all-ceramic crown systems before and after cementation. Operative dentistry. 2012 Oct;37(6):641-9.

35. Groten M, Pröbster L. The influence of different cementation modes on the fracture resistance of feldspathic ceramic crowns. International Journal of Prosthodontics. 1997 Mar 1;10(2).

36. Gassino G, Monfrin SB, Scanu M, Spina G, Preti G. Marginal adaptation of fixed prosthodontics: a new in vitro 360-degree external examination procedure. International Journal of Prosthodontics. 2004 Mar 1;17(2).

37. Anusavice KJ, Carroll JE. Effect of incompatibility stress on the fit of metal-ceramic crowns. Journal of Dental Research. 1987 Aug; 66(8):1341-5.
38. Groten M, Girthofer S, Pröbster L. Marginal fit consistency of copy-milled all-ceramic crowns during fabrication by light and scanning electron microscopic analysis in vitro. Journal of oral rehabilitation. 1997 Dec;24(12):871-81.

39. Groten M, Axmann D, Pröbster L, Weber H. Determination of the minimum number of marginal gap measurements required for practical in vitro testing. The Journal of prosthetic dentistry. 2000 Jan 1;83(1):40-9.

40. Beschnidt SM, Strub JR. Evaluation of the marginal accuracy of different all-ceramic crown systems after simulation in the artificial mouth. Journal of oral rehabilitation. 1999 Jul;26(7):582-93.

41. Güngör MB, Nemli SK. Fracture resistance of CAD-CAM monolithic ceramic and veneered zirconia molar crowns after aging in a mastication simulator. The Journal of prosthetic dentistry. 2018 Mar 1;119(3):473-80.

42. McKague Jr EL, Reynolds JD, Halkias JE. Swelling and glass transition relations for epoxy matrix material in humid environments. Journal of Applied Polymer Science. 1978 Jun;22(6):1643-54.

43. Keenan JD, Seferis JC, Quinlivan JT. Effects of moisture and stoichiometry on the dynamic mechanical properties of a high-performance structural epoxy. Journal of applied polymer science. 1979 Dec 15;24(12):2375-87.

44. Peyser P, Bascom WD. The anomalous lowering of the glass transition of an epoxy resin by plasticization with water. Journal of Materials Science. 1981 Jan 1;16(1):75-83.

45. Barton JM, Greenfield DC. The Use of Dynamic Mechanical Methods to Study the Effect of Absorbed Water on Temperature-dependent Properties of an Epoxy ResinCarbon Fibre Composite. British polymer journal. 1986 Jan;18(1):51-6.

46. Netravali AN, Fornes RE, Gilbert RD, Memory JD. Effects of water sorption at different temperatures on permanent changes in an epoxy. Journal of applied polymer science. 1985 Apr;30(4):1573-8.

47. Luoma GA, Rowland RD. Environmental degradation of an epoxy resin matrix. Journal of applied polymer science. 1986 Nov 20;32(7):5777-90.

48. Chateauminois A, Vincent L, Chabert B, Soulier JP. Study of the interfacial degradation of a glass-epoxy composite during hygrothermal ageing using water diffusion measurements and dynamic mechanical thermal analysis. Polymer. 1994 Oct 1;35(22):4766-74.

49. Liao YT. A study of glass fiber-epoxy composite interfaces. Polymer composites. 1989 Dec;10(6):424-8. 
50. Cairns DS, Adams DF. Moisture and thermal expansion properties of unidirectional composite materials and the epoxy matrix. Journal of reinforced plastics and composites. 1983 Oct;2(4):239-55.

51. Metcalfe AG, Schmitz GK. MECHANISM OF STRESSCORROSION IN E GLASS FILAMENTS. Glass Technology. 1972 Jan 1;13(1):5.

52. Gaur U, Miller B. Effects of environmental exposure on fiber/epoxy interfacial shear strength. Polymer composites. 1990 Aug;11(4):217-22.

53. El-Dessouky RA, Salama MM, Shakal MA, Korsel AM. Marginal adaptation of CAD/CAM zirconia-based crown during fabrication steps. Tanta dental journal. 2015 Jun $1 ; 12(2): 81-8$.

54. Att W, Komine F, Gerds T, Strub JR. Marginal adaptation of three different zirconium dioxide three-unit fixed dental prostheses. The Journal of prosthetic dentistry. $2009 \mathrm{Apr}$ 1;101(4):239-47.

55. Kale E, Seker E, Yilmaz B, Özcelik TB. Effect of cement space on the marginal fit of CAD-CAM-fabricated monolithic zirconia crowns. The Journal of prosthetic dentistry. 2016 Dec 1;116(6):890-5.

56. Kim DY, Kim JH, Kim HY, Kim WC. Comparison and evaluation of marginal and internal gaps in cobalt-chromium alloy copings fabricated using subtractive and additive manufacturing. Journal of prosthodontic research. 2018;62(1):56-64.

57. Ha SJ, Cho JH. Comparison of the fit accuracy of zirconia-based prostheses generated by two CAD/CAM systems. The journal of advanced prosthodontics. $2016 \mathrm{Dec}$ 1;8(6):439-48.

58. Sproesser O, Schmidlin PR, Uhrenbacher J, Eichberger M, Roos M, Stawarczyk B. Work of adhesion between resin composite cements and PEEK as a function of etching duration with sulfuric acid and its correlation with bond strength values. International Journal of Adhesion and Adhesives. 2014 Oct 1;54:184-90.

59. Schmidlin PR, Stawarczyk B, Wieland M, Attin T, Hämmerle $\mathrm{CH}$, Fischer J. Effect of different surface pretreatments and luting materials on shear bond strength to PEEK. Dental materials. 2010 Jun 1;26(6):553-9.

60. Taufall S, Eichberger M, Schmidlin PR, Stawarczyk B. Fracture load and failure types of different veneered polyetheretherketone fixed dental prostheses. Clinical oral investigations. 2016 Dec 1;20(9):2493-500.
61. Sorrentino R, Triulzio C, Tricarico MG, Bonadeo G, Gherlone EF, Ferrari M. In vitro analysis of the fracture resistance of CAD-CAM monolithic zirconia molar crowns with different occlusal thickness. journal of the mechanical behavior of biomedical materials. 2016 Aug 1;61:328-33.

62. Nazari V, Ghodsi S, Alikhasi M, Sahebi M, Shamshiri AR. Fracture strength of three-unit implant supported fixed partial dentures with excessive crown height fabricated from different materials. Journal of Dentistry (Tehran, Iran). 2016 Nov;13(6):400.

63. Fuhrmann G, Steiner M, Freitag-Wolf S, Kern M. Resin bonding to three types of polyaryletherketones (PAEKs) durability and influence of surface conditioning. Dental Materials. 2014 Mar 1;30(3):357-63.

64. Stock V, Schmidlin PR, Merk S, Wagner C, Roos M, Eichberger M, Stawarczyk B. PEEK primary crowns with cobalt-chromium, zirconia and galvanic secondary crowns with different tapers-A comparison of retention forces. Materials. 2016 Mar;9(3):187.

65. Sachdeva S, Kapoor P, Tamrakar AK, Noor R. Nano-composite dental resins: an overview. Annals of Dental Specialty. 2015 Apr 1;3(2):52-5.

66. Stawarczyk B, Thrun H, Eichberger M, Roos M, Edelhoff D, Schweiger J, Schmidlin PR. Effect of different surface pretreatments and adhesives on the load-bearing capacity of veneered 3-unit PEEK FDPs. The Journal of prosthetic dentistry. 2015 Nov 1;114(5):666-73.

67. Stawarczyk B, Ender A, Trottmann A, Özcan M, Fischer $\mathrm{J}$, Hämmerle $\mathrm{CH}$. Load-bearing capacity of CAD/CAM milled polymeric three-unit fixed dental prostheses: effect of aging regimens. Clinical oral investigations. 2012 Dec 1;16(6):1669-77.

68. Stawarczyk B, Özcan M, Trottmann A, Schmutz F, Roos $\mathrm{M}$, Hämmerle C. Two-body wear rate of CAD/CAM resin blocks and their enamel antagonists. The Journal of prosthetic dentistry. 2013 May 1;109(5):325-32.

69. Stawarczyk B, Sener B, Trottmann A, Roos M, Oezcan $\mathrm{M}$, Haemmerle $\mathrm{CH}$. Discoloration of manually fabricated resins and industrially fabricated $\mathrm{CAD} / \mathrm{CAM}$ blocks versus glass-ceramic: effect of storage media, duration, and subsequent polishing. Dental materials journal. 2012; 31(3):377-83.

70. Czasch P, Ilie N. In vitro comparison of mechanical properties and degree of cure of bulk fill composites. Clinical oral investigations. 2013 Jan 1;17(1):227-35. 